\title{
AVALIAÇÃO DA TÉCNICA DE LIXIVIAÇÃO ÁCIDA PARA REDUÇÃO DO TEOR DE FÓŞFORO*
}

\section{Resumo}

Leonardo Martins da Silva ${ }^{1}$ Marisa Nascimento ${ }^{2}$ Izabel de Oliveira Mota ${ }^{3}$ José Adilson de Castro ${ }^{4}$

O minério de ferro quando encontrado contendo teores do elemento fósforo acima de $0,05 \%$ é considerado rejeito dada sua inutilização para o processamento de fabricação do aço. Tal fato ocorre devido a elevação da dureza do aço tornando-o quebradiço e com fratura. Sendo assim o presente trabalho tem como objetivo a avaliação do efeito do processo de lixiviação ácida como finalidade de redução do teor de fósforo no minério de ferro. Através da utilização do software Termocalc® foi possível analisar as diferentes estruturas formadas em diferentes teores do elemento fósforo. Através da técnica de microscopia eletrônica de varredura (MEV) foi possível analisar a estrutura do minério de ferro após seu tratamento com a energia de micro-ondas. Por meio da técnica de planejamento estatístico fatorial com pontos centrais e axiais foi possível determinar as condições ótimas de remoção de fósforo através da técnica de lixiviação ácida

Palavras-chave: Redução de fósforo; Minério de ferro; Lixiviação; Micro-ondas.

\section{EVALUATION OF ACID LEACHING TECHNIQUE FOR REDUCTION OF PHOSPHORUS CONTAINED IN IRON ORE}

\section{Abstract}

Iron ore when found in levels containing the element phosphorus above $0.05 \%$ is considered reject for processing steel fabrication. This fact is due the occurs increase of the hardness of steel making it brittle and fracture. Therefore the present study aims to evaluate the effect of acid leaching process intended to reduce the level of phosphorus in iron ore. Was using the Termocalc $®$ software to parse the different structures formed on different levels of the element phosphorus. Through the technique of scanning (SEM) electron microscopy was analyzed the structure of iron ore after treatment with microwave energy. By means of the factorial statistical design with central and axial points was possible to determine the optimum conditions of phosphorus removal by acid leaching technique.

Keywords: Reduction of phosphorus; Iron ore; Leaching; Microwave.

1 MSc. em Engenharia de Materiais processos químicos e metalúrgicos, Doutorando do PPGEM, UFF, Volta Redonda, RJ, Brasil

2 Ph.D. em Engenharia de materiais e metalurgia na COPPE, UFRJ, Pesquisadora associada do Centro de Tecnologia Mineral (CETEM), MCT, Rio de Janeiro, RJ, Brasil.

3 MSc. em engenharia química na UFRRJ, Doutoranda do PPGEM, UFF, Volta Redonda, RJ, Brasil.

4 Ph.D. em Engenharia Metalúrgica com Foco em simulação de processos. Professor Adjunto da Universidade Federal Fluminense, Volta Redonda RJ, Brasil.

* Contribuição técnica ao 44 Seminário de Redução de Minério de Ferro e Matérias-primas, $15^{\circ}$ Simpósio Brasileiro de Minério de Ferro e 2o Simpósio Brasileiro de Aglomeração de Minério de Ferro, 15 a 18 de setembro de 2014, Belo Horizonte, MG, Brasil. 


\section{INTRODUÇÃO}

O minério de ferro é o recurso mineral metálico extraído em maior volume da crosta terrestre sendo a principal matéria-prima utilizada na indústria siderúrgica [1]. Porém quando encontrado em teores acima do permitido o elemento fósforo torna-se um dos principais contaminantes do minério de ferro afetando assim à qualidade dos produtos siderúrgicos tornando-os com elevada dureza e quebradiços [2]. Sendo assim o teor do elemento fósforo na composição do aço deve ser inferior a 0,05\% todavia no Brasil e em vários locais do mundo são encontradas grandes quantidades de jazidas com teores acima de $0,1 \%$ ocorrendo assim sua desvalorização devido ao alto custo decorrente do processamento de redução do teor de fósforo durante o processo de produção do aço [3]. Tal desvalorização leva ao acumulo de minério de ferro considerado não comercializável e classificado como rejeito.

Segundo Melo [4] no futuro próximo, existe a expectativa de que os minérios lavrados terão teores mais elevados de fosforo e alumina. Sendo assim torna-se imprescindível a redução do teor do elemento fósforo presente no minério de ferro antes da sua utilização na fabricação do aço. Segundo Young shi et al. [5] os principais métodos de remoção do elemento fósforo em partículas de minério de ferro envolvem processos de fundição, separação física e lixiviação química. Foi observado que o processo de fundição tem grande eficácia para a desfosforização do minério de ferro, todavia possui desvantagens como custo muito elevado e necessidades de melhores investigações.

No processo de separação física, os minérios cominuidos devem possuir granulometrias extremamente inferiores com o objetivo da dissociação do mineral fósforo localizado na assembleia mineralógica onde em seguida serão desfosforizado através dos processos de flotação ou separação magnética. Todavia a forma como o elemento fósforo possa estar contido no minério de ferro tem grande influencia no processo de liberação. O elemento fósforo pode estar contido no minério de ferro ligado à molécula de goetita, $\mathrm{FeO}(\mathrm{OH})$, na forma de solução sólida [6]. Porém várias teorias têm sido propostas para explicar a existência de fósforo em goethita. No entanto, nenhuma foi capaz de explicar a desfosforização por lixiviação da goetita. Graham [6] propôs que fósforo elementar existia em solução sólida com goethita. Dukino, [7] contestou esta teoria com base no fato da solução sólida intersticial existir apenas se houver a substituição do cátion por outro de tamanho similar ou menor do que o cátion ligado em sua rede e devendo ainda possuir a mesma carga.

Um mecanismo mais plausível foi proposto por Morris e Barbour, [8-9] e apoiado por Dukino [7], envolvendo superfície de adsorção. Foi sugerido que, antes da desidratação do ferro Hidratado na goethita, um grupo hidroxila da superfície é substituído por um ligante de fosfato, como mostrado no seguinte o modelo:

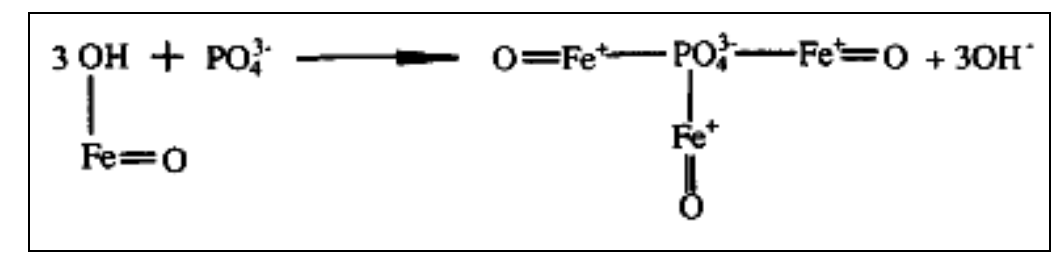

Figura 1. Mecanismo de ocorrencia de fósforo na molécula de goetita

Esta teoria é considerada uma provável explicação da existência de fósforo na goethita. Além disso, esta teoria pode ser usada para explicar a desfosforização.

\footnotetext{
* Contribuição técnica ao $44^{\circ}$ Seminário de Redução de Minério de Ferro e Matérias-primas, 15은 Simpósio Brasileiro de Minério de Ferro e 2o Simpósio Brasileiro de Aglomeração de Minério de Ferro, 15 a 18 de setembro de 2014, Belo Horizonte, MG, Brasil.
} 
Sendo assim a distribuição do elemento fósforo ao longo dos cristais de goetita impede o uso eficaz das técnicas de separação física, requrendo o uso de técnicas de separação química. Segundo Young shi et al [5] o processo de lixiviação química utilizando álcali como agente lixiviante torna-se ineficaz para remoção de fósforo em minérios de ferro devido à ocorrência do processo de reprecipitação do fósforo com outros íons metálicos liberados durante a lixiviação. Sendo assim é constatada que a lixiviação química em meio ácido é a forma mais viável de redução do teor do elemento fósforo contido no minério de ferro. Segundo Peixoto [10] sendo o elemento fósforo encontrado no minério de ferro complexado na estrutura da goetita, ao aplicar-se um tratamento térmico nas partículas do minério é observado um rearranjo estrutural da fase da goetita, que convertido em hematita facilita a liberação do elemento fósforo em ácidos minerais. Para o aquecimento das partículas de minério de ferro foi utilizado energia de micro-ondas. A aplicação de um campo magnético a uma substância diamagnética (com momento magnético nulo na ausência de campo) é responsável pela indução de um momento magnético cuja direção é oposta à do campo externo aplicado. Este é um efeito exatamente oposto ao produzido pelo paramagnetismo, onde o dipolo magnético permanente tende a alinhar-se na mesma direção do campo externo [11]. Quando se utiliza a frequência de $2450 \mathrm{MHz}$, o alinhamento das moléculas e seu retorno ao estado de desordem ocorrem $4,9 \times 10^{9}$ vezes por segundo, o qual resulta em um aquecimento rápido e eficiente. Todavia o aquecimento devido a este processo depende do tempo de relaxação da amostra, sendo definido como o tempo necessário para ordenar totalmente e desordenar $63 \%$ da amostra [12].

Porém para avaliar todos os paramentros e variáveis referentes ao processo de lixiviação química torna-se necessário o uso de uma técnica estatística eficiente de analise multivariada.

Sendo assim este trabalho tem como objetivo através da ultlização do método de planejamento experimental fatorial com pontos axiais e ponto central avaliar os efeitos das principais variáveis referentes ao processo de lixiviação ácida em função da remoção do elemento fósforo incluindo o efeito do processo de aquecimento do minério de ferro, através da interação com a energia de micro-ondas, em testes de laboratório.

\section{MATERIAIS E MÉTODOS}

\subsection{Caracterizações do Minério de Ferro}

As amostras de minério de ferro são originarias da região do Quadrilátero Ferrífero em Minas Gerais, Brasil. Todas as amostras foram cominuídas em moinho de barras nas instalações do Centro de Tecnologia Mineral gerando Frações granulométricas de 28, 35, 48 e 200 mesh.

A análise química foi realizada utilizando a técnica de difração de raio $x$ através do método de Rietvelt, que tem por base a simulação de todo um perfil difratométrico partindo de parâmetros estruturais das fases componentes de uma amostra, permitindo que maiores informações possam ser extraídas dos difratogramas. 


\subsection{Processo de Lixiviação}

Para a realização do processo de lixiviação foi utilizado um becher de $500 \mathrm{ml}$ sendo adicionada em $250 \mathrm{ml}$ de ácido sulfurico na concentração de 0,2 molar. Diferentes massas de minério de ferro em diferentes tamanhos granulométricos foram agitadas em um agitador mecanico digital modelo IKA RW 20 com display digital. O lixiviado da amostra do minério de ferro foi filtrado em um filtro à vácuo e o licor de lixiviação foi separado gerando assim a amostra do minério de ferro lixiviado. A amostra do minério de ferro foi seca em estufa a $40^{\circ} \mathrm{C}$ e em seguida homogeneizada e levada para análise. A quantificação do fósforo foi realizada pelo Laboratório de Análise Química localizada no Centro de Tecnologia Mineral mantido pelo Ministério da Ciencia e Tecnologia (CETEM / MCT), onde foi utilizada a técnica de espectroscopia de emissão ótica com plasma indutivamente acoplado (ICP-OES). Neste trabalho foi utilizado para o processo de aquecimento do minério através da energia de microondas um forno convencional onde o qual possui $1200 \mathrm{w}$ de potência e $2450 \mathrm{MHZ}$ de frequência. Para captação da temperatura foi utilizado termopares do tipo $k$ onde associado a um software foi possível medir o aumento da temperatura do minério de ferro em contato com a energia de microondas apresentada na Figura 5, sendo demonstrado o aumento de temperatura em função do tamanho granulométrico dado em microns.

\subsection{Análises Estatística}

Para análise do processo de lixiviação foi escolhido o planejamento experimental fatorial com dois pontos axiais e um ponto central tendo sete variáveis independentes sendo:

- Velocidade de lixiviação;

- Tempo;

- Tamanho granulométrico;

- Concentração de minério na solução;

- Concentração da solução lixiviante e

- Tempo de contato da amostra de minério de ferro com micro-ondas.

Em um experimento tão pequeno quanto este pode ser mais adequado, em termos de estimação do resíduo, repetir-se ensaios nos quatros pontos fatoriais [13]. Para analise estatística foi utilizado o software Statistica 8.0 desenvolvido pela empresa Statsoft onde foi possível analisar estatisticamente os resultados obtidos.

\section{RESULTADOS E DISCUSSÃO}

\subsection{Caracterizações do Minério de Ferro}

$\mathrm{Na}$ amostra de minério de ferro através da técnica de difração de raio $\mathrm{x}$ utilizando o método de Rietvelt indicou que o teor de fósforo na amostra de minério de ferro foi encontrado na concentração de $400 \mathrm{mg} / \mathrm{kg}$ o que corresponde a $0,04 \%$. O padrão de difração de raios-X da amostra de minério é apresentado na Fig. 1 , e indica que o minério é composto principalmente de caulinita $4,64 \%$, gibbsita $3,18 \%$, goethita $7,25 \%$, hematita $72,89 \%$ e quartzo $12,05 \%$ como mostrado na Tabela 2 . A ausencia de compostos fosfatados aluminosos indica que o fósforo ocorre na estrutura da goethita formando um complexo estável.

\footnotetext{
* Contribuição técnica ao 44 Seminário de Redução de Minério de Ferro e Matérias-primas, 15ํ Simpósio Brasileiro de Minério de Ferro e $2^{\circ}$ Simpósio Brasileiro de Aglomeração de Minério de Ferro, 15 a 18 de setembro de 2014, Belo Horizonte, MG, Brasil.
} 


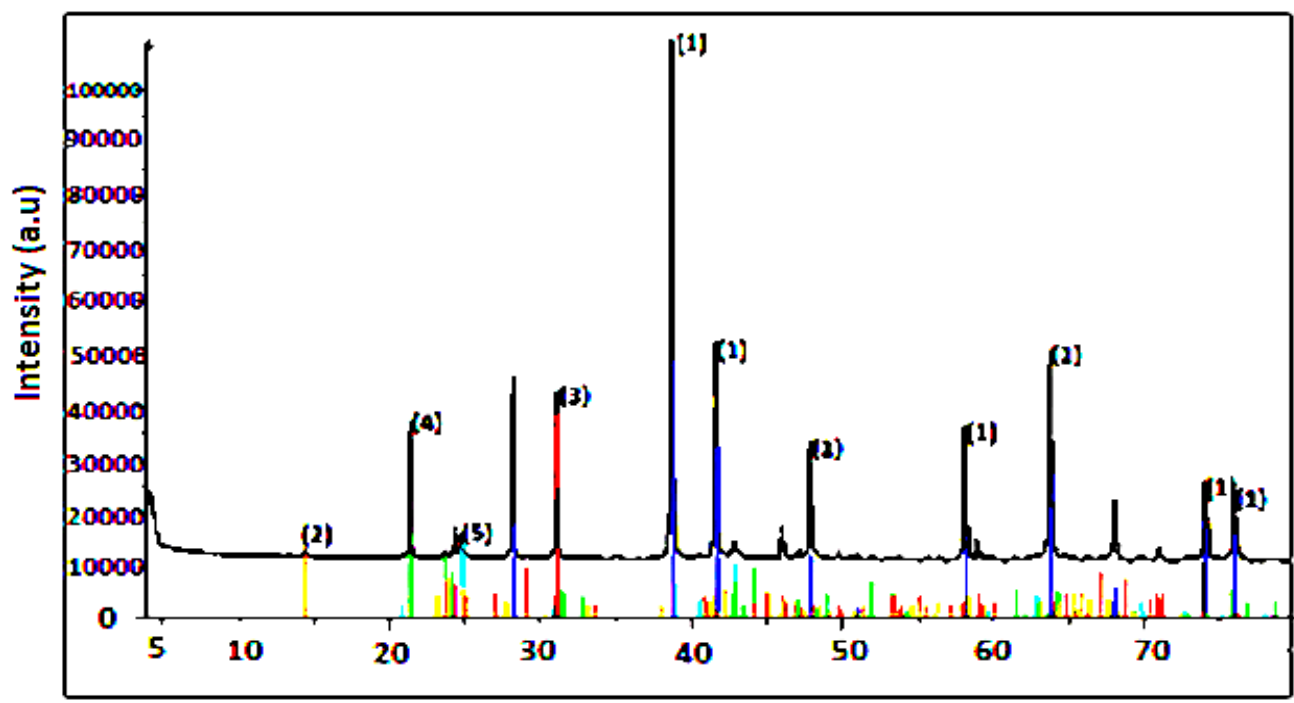

$2 \theta$ degrees

Figura 2. Espectro de difração de raio $X$ da amostra de minério de ferro

Tabela 1. Composição mineralógica da amostra de minério de ferro (\% por massa)

\begin{tabular}{lc}
\hline MINERAL & FRAÇÂO MÁSSICA, \% \\
\hline HEMATITA $\left(\mathrm{Fe}_{2} \mathrm{O}_{3}\right)(1)$ & 72,89 \\
CAOLINITE $\left[\mathrm{Al}_{2} \mathrm{Si}_{2} \mathrm{O}_{5}(\mathrm{OH})_{4}\right](2)$ & 4,64 \\
QUARTZO $\left(\mathrm{SiO}_{2}\right)(3)$ & 12,05 \\
GIBSITA $\left[\mathrm{AI}(\mathrm{OH})_{3}\right]{ }^{(4)}$ & 3,18 \\
GOETITA $[\mathrm{FeO}(\mathrm{OH})](5)$ & 7,25 \\
\hline
\end{tabular}

Na Figura 3 é demonstrado o diagrama de fase do minério de ferro na composição de Fe $60 \%$, O 20\%, Si 10\%, Al 9,99\%. Calculado utilizando o software Thermocalc®.

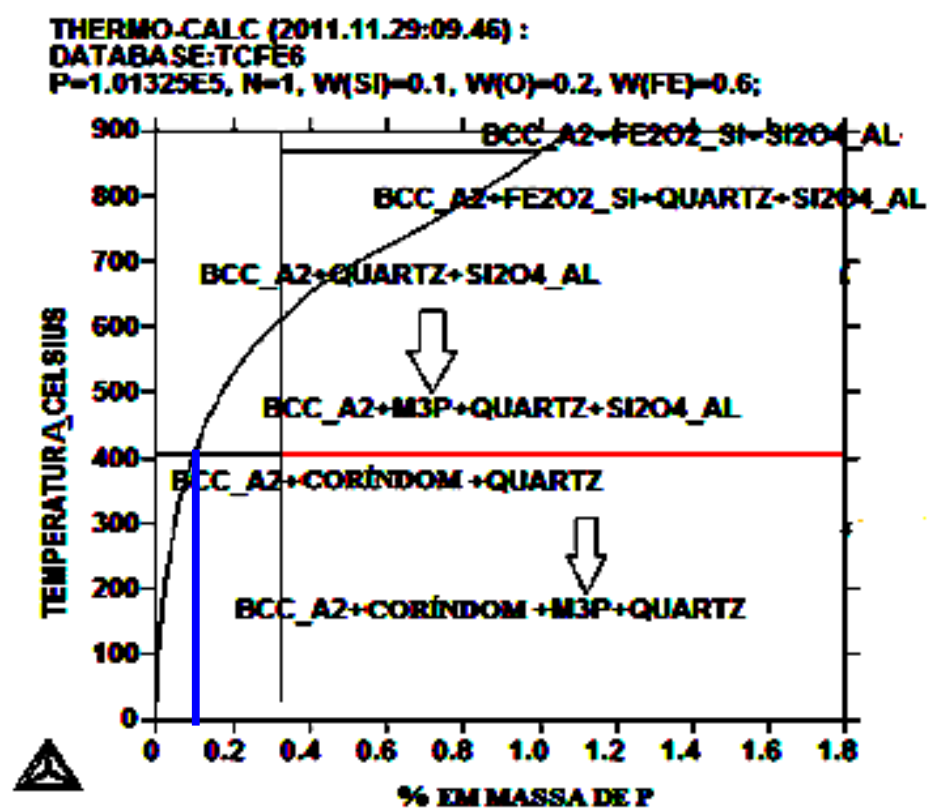

Figura 3. Diagrama de fase do minério de ferro de composição: Fe $60 \%$, O 20\%, Si 10\%, Al 9,99\%. Calculado utilizando o software Thermocalc ${ }^{\circledR}$.

Na Figura 3 é demonstrado o diagrama de fase do minero de ferro em diferentes porcentagens em massa de $\mathrm{P}$ onde é demonstrado em temperaturas de 0 a $400^{\circ} \mathrm{C}$

* Contribuição técnica ao 44 Seminário de Redução de Minério de Ferro e Matérias-primas, 15은 Simpósio Brasileiro de Minério de Ferro e $2^{\circ}$ Simpósio Brasileiro de Aglomeração de Minério de Ferro, 15 a 18 de setembro de 2014, Belo Horizonte, MG, Brasil. 
em uma composição de $0,1 \%$ em massa de fósforo a existência do complexo M3P onde o qual vai de encontro ao complexo demonstrado por Dukino onde o fósforo aparece complexado com 3 moléculas de goetita. Todavia acima de $400^{\circ} \mathrm{C}$ em uma composição de $0,1 \%$ em massa de fósforo é demonstrada a não existência do complexo M3P.

Segundo Graham [6] a calcinação do minério de ferro causa desidratação da goetita para hematita, liberando o fósforo em solução como um composto solúvel em ácido.

Porém, com o uso da energia de microondas pode-se obter vantagens adicionais ao aquecimento. Segundo Haque [14] foi observado através do contato com a energia de microondas a ocorrencia de diferentes taxas de aquecimento em diferentes minerais presentes na estrutura do minério de ferro causando tensões térmicas e fraturas nas partículas.

Fraturas as quais podem gerar vantagens referente aumento da superficie de contato com o meio lixiviante.

\subsection{Análise Estatística}

\subsubsection{Adições de pontos axiais}

O Projeto de delineamento composto central (DCC) incluindo foi utilizado para identificar o valor mais preciso para a resposta real. Os efeitos das variáveis independentes, que consiste de variáveis referentes ao processo de lixiviação (tempo de contato; concentração de minério; tempo de lixiviação; temperatura de lixiviação; granulometria média; velocidade de agitação e tempo de contato com a energia de microondas) foram avaliadas neste estudo. A Tabela 2 apresenta os valores utilizados no planejamento fatorial.

Todavia pode ser mais adequado, em termos de estimação do resíduo, repetir-se ensaios nos quatros pontos fatoriais. No entanto ensaios no ponto central podem fornecer informações úteis sobre o comportamento das respostas entre os níveis inicialmente atribuídos aos fatores podendo também evidenciar a qualidade da repetitividade do processo. Deve-se, portanto repetir ensaios nos pontos axiais e realizar alguns ensaios no ponto central [13].

Um delineamento Composto Central Rotacional com 2 níveis originais, faz-se necessário $2^{5}$ pontos fatoriais $+2 \times 6$ pontos axiais + um número arbitrário de pontos centrais.

A Tabela 2 apresenta os valores utilizados no planejamento fatorial.

Tabela 2. Níveis utilizados no planejamento fatorial

\begin{tabular}{|c|c|c|c|c|c|}
\hline Variáveis & $-1,68$ & -1 & 0 & 1 & $+1,68$ \\
\hline Concentração (g/1000ml) & 2 & 27 & 52 & 77 & 102 \\
\hline $\begin{array}{l}\text { Tempo de lixiviação } \\
\text { (min) }\end{array}$ & 2 & 20 & 38 & 56 & 74 \\
\hline Temperatura $\left({ }^{\circ} \mathrm{C}\right)$ & 5 & 25 & 45 & 65 & 85 \\
\hline $\begin{array}{l}\text { Granulometria média } \\
\text { (microns) }\end{array}$ & 75 & 595 & 500 & 297 & 2380 \\
\hline Velocidade de agtação & 155 & 310 & 620 & 465 & 775 \\
\hline $\begin{array}{l}\text { Tempo de contato no } \\
\text { microondas }\end{array}$ & 0 & 1 & 2 & 3 & 4 \\
\hline
\end{tabular}

$\mathrm{Na}$ Tabela 3 são apresentados os valores experimentais seguida da variável resposta porcentagem de remoção do elemento fósforo.

* Contribuição técnica ao 44 Seminário de Redução de Minério de Ferro e Matérias-primas, 15은 Simpósio Brasileiro de Minério de Ferro e 2 Simpósio Brasileiro de Aglomeração de Minério de Ferro, 15 a 18 de setembro de 2014, Belo Horizonte, MG, Brasil. 
Tabela 3. Planejamento fatorial e variável resposta.

\begin{tabular}{|c|c|c|c|c|c|c|c|c|}
\hline Ensaio & $\begin{array}{c}\text { Massa } \\
\text { tabelada } \\
(\mathrm{g})\end{array}$ & $\begin{array}{l}\text { Tempo } \\
\text { (min) }\end{array}$ & $\begin{array}{c}\text { Temperatura } \\
\left({ }^{\circ} \mathrm{C}\right)\end{array}$ & $\begin{array}{l}\text { Tamanho } \\
\text { (microns) }\end{array}$ & $\begin{array}{l}\text { Veloc de } \\
\text { agitação } \\
\text { (rpm) }\end{array}$ & $\begin{array}{l}\text { Tempo de contato } \\
\text { com a energia de } \\
\text { microondas (min) }\end{array}$ & $\begin{array}{c}\text { Remoção } \\
\text { p (\%) }\end{array}$ & $\begin{array}{l}\text { Remoção } \\
\text { de Fe }\end{array}$ \\
\hline 1 & 6,75 & 20 & 25 & 595 & 310 & 4 & 6,59 & 0,117 \\
\hline 2 & 19,25 & 20 & 25 & 595 & 310 & 3 & 9,29 & 0,024 \\
\hline 3 & 6,75 & 56 & 25 & 595 & 310 & 3 & 7,16 & 0,045 \\
\hline 4 & 19,25 & 56 & 25 & 595 & 310 & 1 & 4,23 & 0,012 \\
\hline 5 & 6,75 & 20 & 65 & 595 & 310 & 3 & 8,92 & 0,108 \\
\hline 6 & 19,25 & 20 & 65 & 595 & 310 & 1 & 11,90 & 0,084 \\
\hline 7 & 6,75 & 56 & 65 & 595 & 310 & 1 & 10,64 & 0,098 \\
\hline 8 & 19,25 & 56 & 65 & 595 & 310 & 3 & 44,30 & 0,095 \\
\hline 9 & 6,75 & 20 & 25 & 297 & 310 & 3 & 7,05 & 0,036 \\
\hline 10 & 19,25 & 20 & 25 & 297 & 310 & 1 & 7,84 & 0,012 \\
\hline 11 & 6,75 & 56 & 25 & 297 & 310 & 1 & 7,97 & 0,050 \\
\hline 12 & 19,25 & 56 & 25 & 297 & 310 & 3 & 17,90 & 0,056 \\
\hline 13 & 6,75 & 20 & 65 & 297 & 310 & 1 & 14,31 & 0,064 \\
\hline 14 & 19,25 & 20 & 65 & 297 & 310 & 3 & 18,87 & 0,255 \\
\hline 15 & 6,75 & 56 & 65 & 297 & 310 & 3 & 19,62 & 0,352 \\
\hline 16 & 19,25 & 56 & 65 & 297 & 310 & 1 & 15,76 & 0,234 \\
\hline 17 & 6,75 & 20 & 25 & 595 & 620 & 3 & 8,74 & 0,082 \\
\hline 18 & 19,25 & 20 & 25 & 595 & 620 & 1 & 5,29 & 0,014 \\
\hline 19 & 6,75 & 56 & 25 & 595 & 620 & 1 & 12,44 & 0,015 \\
\hline 20 & 19,25 & 56 & 25 & 595 & 620 & 3 & 10,01 & 0,032 \\
\hline 21 & 6,75 & 20 & 65 & 595 & 620 & 1 & 15,17 & 0,070 \\
\hline 22 & 19,25 & 20 & 65 & 595 & 620 & 3 & 52,47 & 0,101 \\
\hline 23 & 6,75 & 56 & 65 & 595 & 620 & 3 & 26,04 & 0,215 \\
\hline 24 & 19,25 & 56 & 65 & 595 & 620 & 1 & 38,16 & 0,216 \\
\hline 25 & 6,75 & 20 & 25 & 297 & 620 & 1 & 16,92 & 0,028 \\
\hline 26 & 19,25 & 20 & 25 & 297 & 620 & 3 & 19,96 & 0,034 \\
\hline 27 & 6,75 & 56 & 25 & 297 & 620 & 3 & 14,25 & 0,016 \\
\hline 28 & 19,25 & 56 & 25 & 297 & 620 & 1 & 13,74 & 0,013 \\
\hline 29 & 6,75 & 20 & 65 & 297 & 620 & 3 & 18,13 & 0,046 \\
\hline 30 & 19,25 & 20 & 65 & 297 & 620 & 1 & 25,82 & 0,138 \\
\hline 31 & 6,75 & 56 & 65 & 297 & 620 & 1 & 21,95 & 0,101 \\
\hline 32 & 19,25 & 56 & 65 & 297 & 620 & 3 & 47,57 & 0,530 \\
\hline 33 & 13 & 38 & 45 & 500 & 465 & 2 & 17,40 & 0,059 \\
\hline 34 & 13 & 38 & 45 & 500 & 465 & 2 & 16,40 & 0,057 \\
\hline 35 & 13 & 38 & 45 & 500 & 465 & 2 & 20,75 & 0,076 \\
\hline 36 & 13 & 38 & 45 & 500 & 465 & 2 & 23,78 & 0,110 \\
\hline 37 & 0,5 & 38 & 45 & 500 & 465 & 2 & 61,25 & 0,098 \\
\hline 38 & 25,5 & 38 & 45 & 500 & 465 & 2 & 24,95 & 0,113 \\
\hline 39 & 13 & 2 & 45 & 500 & 465 & 2 & 9,18 & 0,014 \\
\hline 40 & 13 & 74 & 45 & 500 & 465 & 2 & 26,18 & 0,130 \\
\hline 41 & 13 & 38 & 5 & 500 & 465 & 2 & 8,27 & 0,008 \\
\hline 42 & 13 & 38 & 85 & 500 & 465 & 2 & 27,03 & 0,254 \\
\hline 43 & 13 & 38 & 45 & 2380 & 465 & 2 & 34,24 & 0,036 \\
\hline
\end{tabular}

* Contribuição técnica ao $44^{\circ}$ Seminário de Redução de Minério de Ferro e Matérias-primas, 15o Simpósio Brasileiro de Minério de Ferro e 2o Simpósio Brasileiro de Aglomeração de Minério de Ferro, 15 a 18 de setembro de 2014, Belo Horizonte, MG, Brasil. 


\subsection{Efeitos da Massa; Tempo de Contato com a Energia de Microondas e Tamanho de Partícula do Minério de Ferro para o Processo de Lixiviação}

Nas Figuras 4a e 4b são demonstrados os perfis de redução do teor de fósforo em função da massa, tamanho de partícula e do tempo de contato da amostra com a energia de microondas.

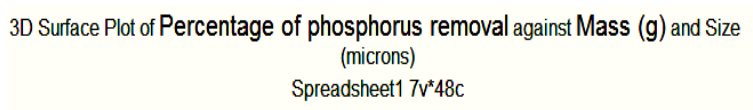

3D Surface Plot of Percentage of phosphorus removal against Mass ( $\mathrm{g}$ ) and Size (microns)

Spreadsheet $17 v^{*} 48 c$

Percentage of phosphorus removal $=$ Distance Weighted Least Squares

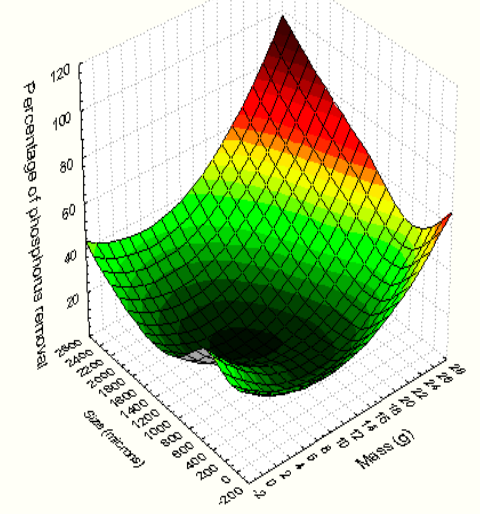

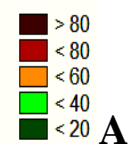

3D Surface Plot of Percentage of phosphorus removal against Mass $(\mathrm{g})$ and Con time with the microwave energy (min) Spreadsheet $17 v^{*} 48 \mathrm{c}$

Percentage of phosphorus removal $=$ Distance Weighted Least Squares

\section{B}

Figura 4a. Evolução da redução do teor do elemento fósforo em função do aumento de massa e do tamanho granulométrico. Figura $\mathbf{4 b}$ evolução da redução do teor do elemento fósforo em função do aumento de massa da amostra e do aumento do tempo de contado do minério de ferro e a energia de microondas.

* Contribuição técnica ao $44^{\circ}$ Seminário de Redução de Minério de Ferro e Matérias-primas, 15은 Simpósio Brasileiro de Minério de Ferro e $2^{\circ}$ Simpósio Brasileiro de Aglomeração de Minério de Ferro, 15 a 18 de setembro de 2014, Belo Horizonte, MG, Brasil. 
Foi observado na Figura 4A a evolução da redução do teor do elemento fósforo em função do aumento de massa e do tamanho granulométrico superior.

$\mathrm{Na}$ Figura 4B foi observado a evolução da redução do teor do elemento fósforo em função do aumento de massa da amostra e também do aumento do tempo de contado do minério de ferro e a energia de microondas. Foi demonstrado maiores valores de redução do teor do elemento fósforo em 500 micrometros e $19,25 \mathrm{~g}$ de minério de ferro tendo a amostra de minério permanecido por 3 minutos em contato com a energia de microondas.

Segundo Wen-tang et al [15] a taxa de desfosforação diminui ligeiramente com o aumento do tamanho de partícula. Tal fato indica que a molécula de fosfato no minério não precisa estar completamente dissociada e a reação pode acontecer em partículas com valores granulométricos maiores.

Segundo Hake [14] o aquecimento rápido de minérios no microondas no minério com matriz transparente gera estresse térmico de magnitude suficiente para criar microfissuras ao longo dos limites de grão dos minerais. Este tipo de microfissuras tem elevada potencialidade na melhoraria da eficiência dos processos de cominuição e lixiviação.

\subsection{Efeitos da Massa; Velocidade de Agitação e Temperatura do Processo de Lixiviação}

Nas figuras $5 a$ e $5 b$ são demonstrados os perfis de redução do teor de fósforo em função da massa da amostra, da velocidade de agitação da partícula de minério de ferro e da temperatura do processo de lixiviação.

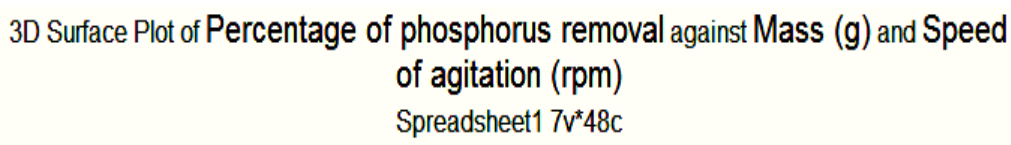

Percentage of phosphorus removal = Distance Weighted Least Squares

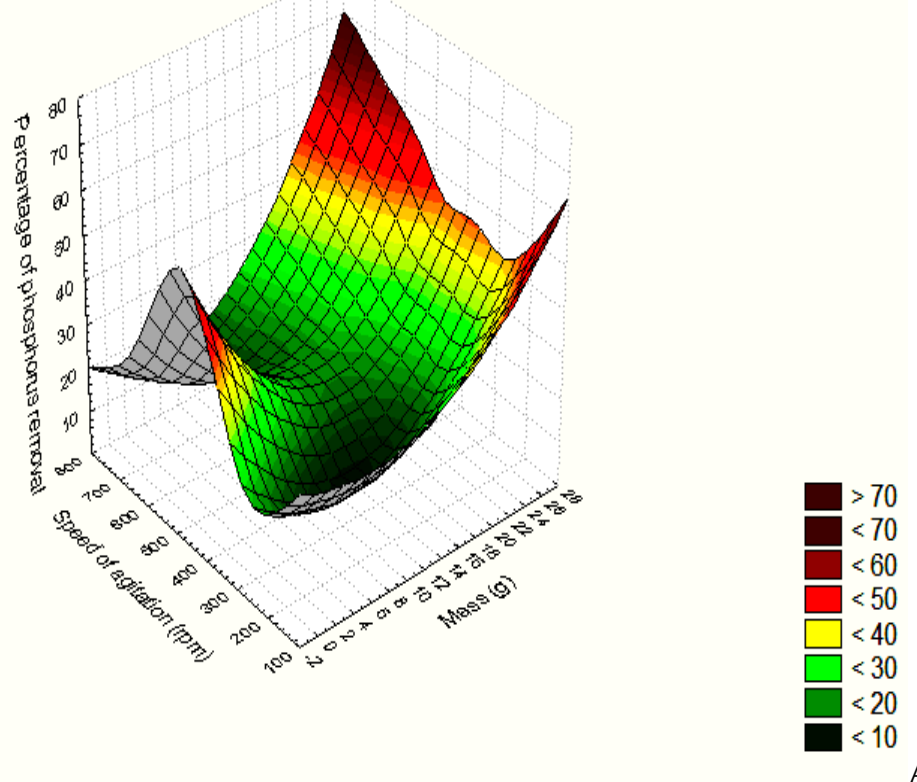

* Contribuição técnica ao 44 Seminário de Redução de Minério de Ferro e Matérias-primas, 15 Simpósio Brasileiro de Minério de Ferro e 2ํ Simpósio Brasileiro de Aglomeração de Minério de Ferro, 15 a 18 de setembro de 2014, Belo Horizonte, MG, Brasil. 


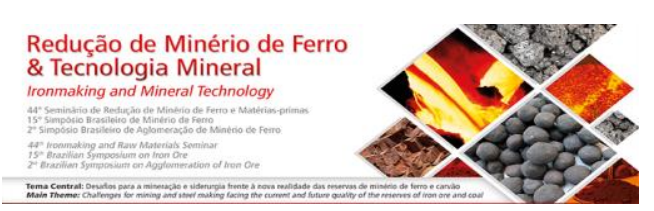

3D Surface Plot of Percentage of phosphorus removal against Mass $(\mathrm{g})$ and

Temperature $\left({ }^{\circ} \mathrm{C}\right)$

Spreadsheet $17 \mathrm{v}^{*} 48 \mathrm{c}$

Percentage of phosphorus removal $=$ Distance Weighted Least Squares

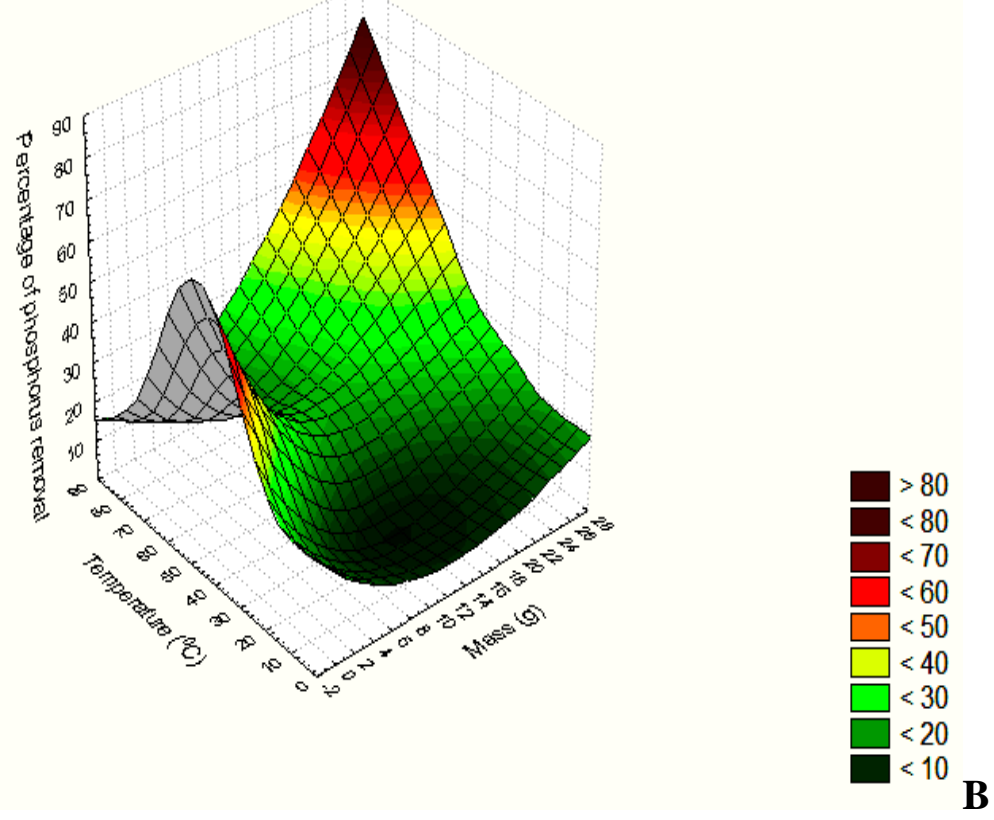

Figura 5a. Perfis de redução do teor de fósforo em função da massa da amostra, da velocidade de agitação da partícula de minério de ferro. Figura $\mathbf{5 b}$ perfis de redução do teor de fósforo em função da massa da amostra e da temperatura do processo de lixiviação.

Nas Figura $5 a$ e 5b, foi observada o perfil de evolução da redução do teor do elemento fósforo em função do aumento de massa, velocidade de agitação e temperatura de lixiviação. Foi demonstrado que ambos adquirem melhor taxa de remoção em valores de temperatura de $65^{\circ} \mathrm{C}$ tendo a velocidade de agitação de 620rpm. Segundo Young-Shi [5] a melhor velocidade de agitação para remoção de fósforo foi de 620rpm sendo a perda de ferro durante o processo negligenciável. Porém Segundo Cheng et al. [3] usando ácido sulfúrico foi demonstrado ser a temperatura de $65^{\circ} \mathrm{C}$ como a temperatura ótima de remoção de fósforo durante 0 processo de lixiviação.

\subsection{Efeitos da Massa e do tempo do processo de lixiviação:}

Na Figura 6 é demonstrado o perfil de redução do teor de fósforo em função da massa e do tempo de lixiviação da amostra de minério de ferro.

* Contribuição técnica ao $44^{\circ}$ Seminário de Redução de Minério de Ferro e Matérias-primas, 15o Simpósio Brasileiro de Minério de Ferro e 2o Simpósio Brasileiro de Aglomeração de Minério de Ferro, 15 a 18 de setembro de 2014, Belo Horizonte, MG, Brasil. 
3D Surface Plot of Percentage of phosphorus removal against Mass (g) and Time $(\min )$

Spreadsheet1 $7 v^{\star} 48 c$

Percentage of phosphorus removal $=$ Distance Weighted Least Squares

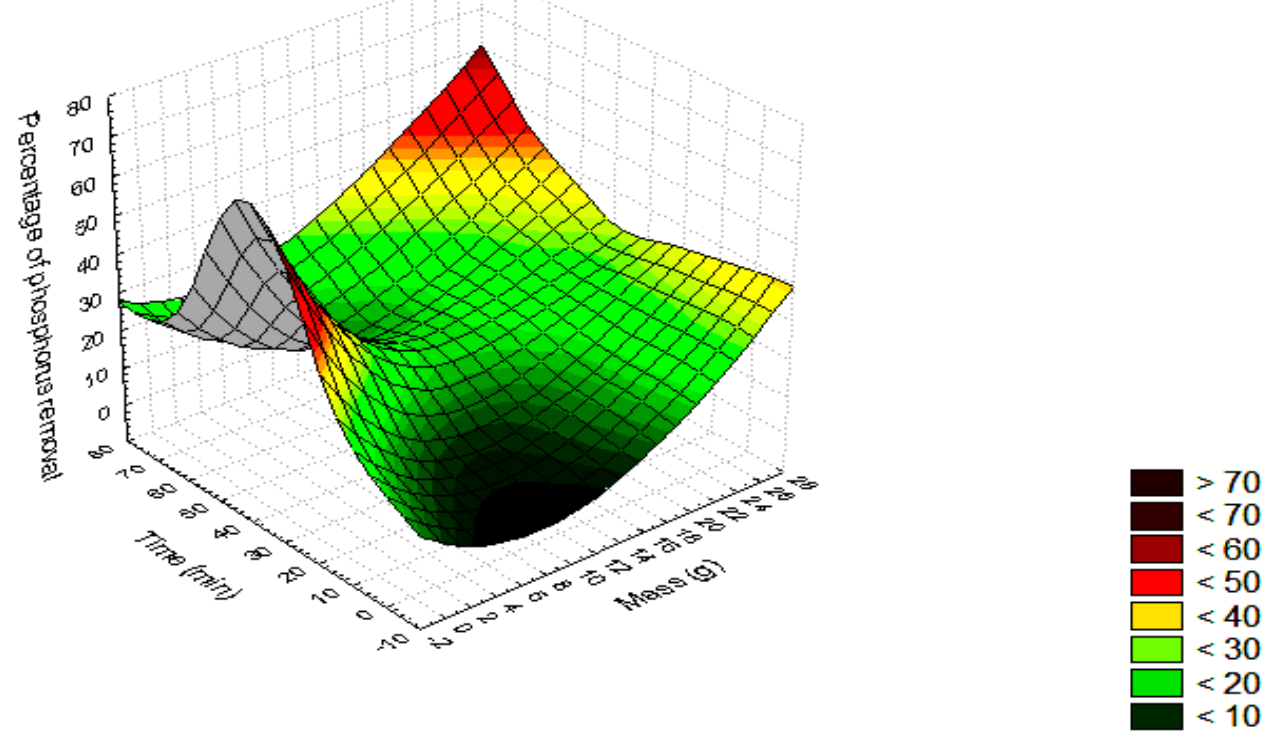

Figura 6. Perfil de redução do teor de fósforo em função da massa e do tempo de lixiviação da amostra de minério de ferro.

Na Figura 6 foi apresentado o perfil de redução do teor de fósforo em função da massa e do tempo de lixiviação da amostra de minério de ferro sendo demonstrado o valor de 20 min como o melhor tempo de remoção de fósforo.

Segundo yong-shi [5] o ácido sulfúrico remove o elemento fósforo das partículas de minério de ferro com mais eficiência durante 20 min de lixiviação.

\subsection{Pré-Tratamento do Minério de Ferro}

Segundo Antonucci e Correa [16] foi realizada uma reação de sulfatação por aquecimento por microondas utilizando a frequência de $2.450 \mathrm{MHz}$ em uma mistura de concentrado e de ácido sulfúrico seguido de lixiviação em água a $60^{\circ} \mathrm{C}$ tendo como resultado uma extração de cobre superior a $96 \%$ foi concluido que, embora este processo exigisse mais energia do que o processo convencional de fundição 0 resultado final foi vantajoso.

Na Figura 4 são apresentadas micrografias de minério de ferro de diferentes frações granulométricas.

* Contribuição técnica ao 44 Seminário de Redução de Minério de Ferro e Matérias-primas, 15ํ Simpósio Brasileiro de Minério de Ferro e $2^{\circ}$ Simpósio Brasileiro de Aglomeração de Minério de Ferro, 15 a 18 de setembro de 2014, Belo Horizonte, MG, Brasil. 


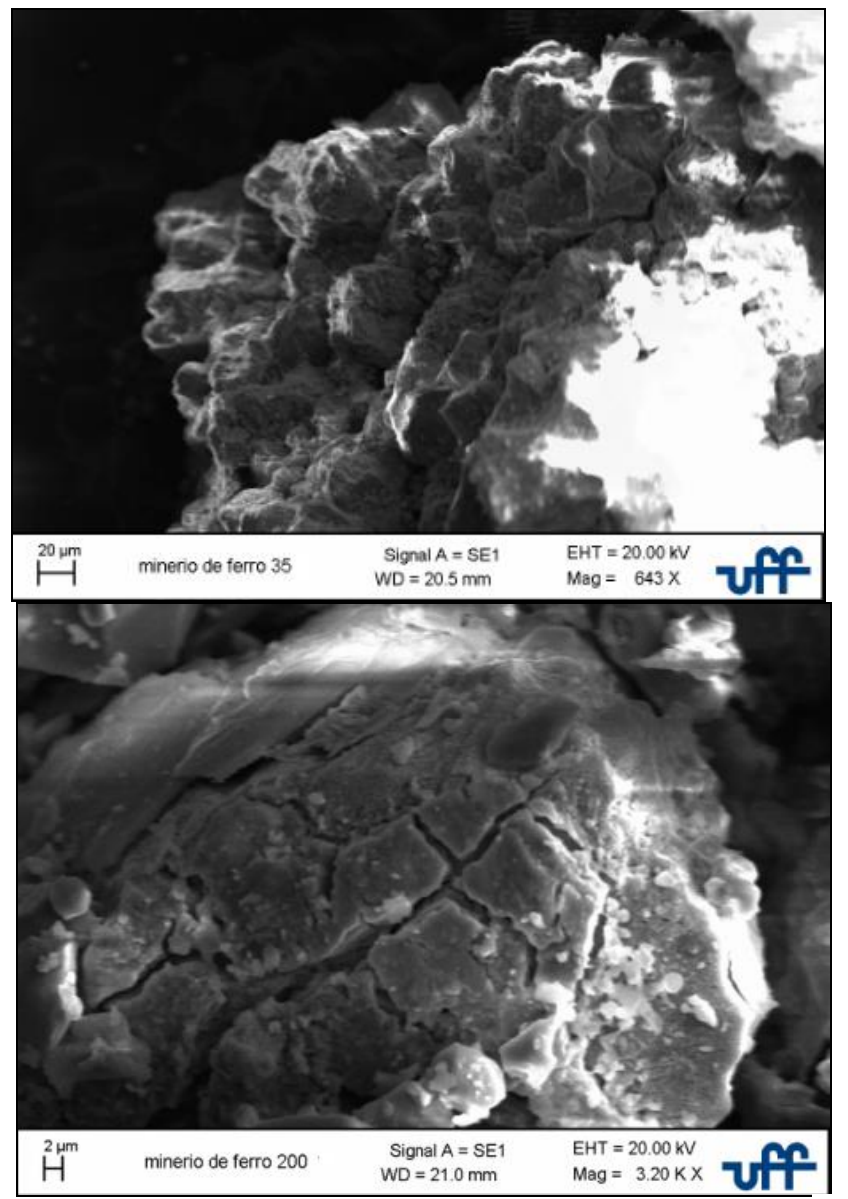

Figura 7. Micrografias do minério de ferro em 35 e $200 \mu \mathrm{m}$.

Na Figura 7 é observada, através das imagens geradas por microscopia eletronica de varredura, a formação de porosidade nas partículas de minério de ferro em diferentes granulometrias.

Porém Na Figura 7 foi observado o aumento da redução do elemento fósforo no minério de ferro em função do aumento do tempo de contato da amostra do minério de ferro com a energia de microondas. Segundo Haque [14] a temperatura máxima atingida, a saturação de magnetismo e a magnetização remanescente das amostras de minério de ferro aumentam com o aumento do tempo de radiação de microondas no minério de ferro. O trabalho realizado por Roy e Agrawal [11] mostraram que a interação do campo magnético com alguns materiais contribui muito na taxa de aquecimento comparado aos materiais expostos ao campo elétrico.

Segundo Haque [14] A energia de micro-ondas fornece um possível mecanismo para induzir a ruptura entre os minerais de valor no minério e a ganga, ou rocha hospedeira, devido ao diferencial na absorção de energia das micro-ondas e as diferenças térmicas dadas pelos coeficientes de expansão entre as várias fases minerais nas partículas do minério de ferro.

\section{CONCLUSÃO}

Com a finalidade de avaliar as variáveis encontradas no processo de lixiviação para redução do teor de fósforo em amostras de minério de ferro extraídas da região do quadrilátero ferrífero, Brasil. Portanto foram tiradas as seguintes conclusões:

- A massa em gramas da amostra de minério de ferro onde se obtém a melhor taxa de remoção foi de $19,25 \mathrm{~g}$ em $250 \mathrm{ml}$ de solução de ácido sulfúrico na

* Contribuição técnica ao $44^{\circ}$ Seminário de Redução de Minério de Ferro e Matérias-primas, 15o Simpósio Brasileiro de Minério de Ferro e 2o Simpósio Brasileiro de Aglomeração de Minério de Ferro, 15 a 18 de setembro de 2014, Belo Horizonte, MG, Brasil. 
concentração de $0,2 \mathrm{M}$, porém nesta concentração ocorre maiores dissociações do hidrogênio existente nas moléculas de ácido sulfúrico.

- O aumento de temperatura foi favorável para o processo de lixiviação atingindo o limite de $65^{\circ} \mathrm{C}$ demonstrando ser endotérmica a reação de formação de ácido fosfórico utilizando o ácido sulfúrico.

- Foi observado que a melhor velocidade de agitação para o processo de lixiviação foi de $620 \mathrm{rpm}$ onde em velocidades superiores foi observado 0 decréscimo da remoção do elemento fósforo do minério de ferro. Fato ocorrido devido ao vórtice formado no centro do reator onde o qual deposita as partículas no fundo do reato diminuindo o contato entre as partículas e 0 meio lixiviante.

- A granulometria ótima para o processo de remoção de fósforo foi de 580 microns onde foi observado em granulometrias inferiores e superiores o processo de deposição da amostra de minério de ferro no fundo do reator ocorrendo assim vista a baixa agitação observada nas partículas a diminuição da intensidade do processo de lixiviação onde consequentemente ocorre 0 decréscimo na redução do teor de fósforo da amostra de minério de ferro.

- O tempo observado para a melhor taxa de remoção do minério de ferro através do processo de lixiviação foi de 20 minutos onde após o tempo decorrido foi observado baixa taxa de redução do fósforo presente na amostra de minério.

- O processo de remoção do fósforo foi altamente favorecido através do aumento do tempo de contato do minério de ferro com a energia de microondas. Tal fato é devido ao complexo formado entre o elemento fósforo com o mineral goetita onde devido ao aquecimento do minério de ferro ocorreu-se um rearranjo liberando assim o mesmo para a solução lixiviante onde devido fraturas geradas através do choque térmico com a água na temperatura ambiente ocorrendo assim um aumento significativo na superfície de contato entre o mineral e a solução lixiviante.

- Perda de ferro durante a lixiviação ácida pode ser considerado insignificante, sendo menor que $0,4 \%$.

- O baixo consumo de ácido foi considerado um fator importante para a viabilidade do processo seguido pela possibilidade reciclagem da solução de ácido sulfúrico podendo também ser incorporado na lixiviação do minério de ferro tornando o processo de desfosforização ainda mais econômico.

\section{Agradecimentos}

Os autores agradecem aos órgãos financiadores: Coordenação de Aperfeiçoamento de Pessoal de Nível Superior, Ministério da ciência e tecnologia. Agradecem também a equipe do Centro de Tecnologia Mineral pelo desenvolvimento dos ensaios e análises químicas e ao programa de pós-graduação em Engenharia Metalúrgica da Universidade Federal Fluminense pelo apoio técnico científico. 


\section{REFERÊNCIAS}

1 Damasceno CE. Disponibilidade, suprimento e demanda de minérios para metalurgia. Rio de janeiro: Série estudos e documentos, v.1) Cetem/MCT, 2007.145p

2 Vieira CB, Rosière AC, Pena EQ, Seshadri VS, Assis PS.; avaliação técnica de minérios de ferro para sinterização nas siderúrgicas e minerações brasileiras: uma análise crítica. Revista Escola de Minas, 2003; 56(2): 40-42. Ouro Preto.

3 Cheng CY, Misra VN, Clough J, Mun R. Dephosphorisation Of Western Australian Iron Ore By Hydrometallurgical Process Div. of Minerals, PO Box 90, Bentley, WA 6982, Australia, p. 1024 - 1025 Maio/abril de 1999.

4 Melo L. C. P Siderurgia no Brasil 2010-2025; subsidios para tomada de decisao Brasilia: Centro de Gestao e Estudos Estrategicos, 2010.112p.

5 Yong-shi J, Jiang TY, Yong-Bin LI, Qian LI Guang-Hui G, Yu-Feng. Removal of phosphorus from iron ores by chemical leaching School of Minerals Processing and Bioengineering, Central South University, Changsha 410083, China 2006.

6 Graham J. Phosphorus in iron ore from the Hamersley iron formations, Proceedings of the Australasian Institute of Mining and Metallurgy, No. 246, p. 41-42. 1973.

7 Dukino R. Phosphorus in Hamersley Range iron ore, BHP Internal Report,USA, 1997.

8 Morris RC. A pilot study of phosphorus distribution in parts of the Brockman iron formation, Hamersley Group Internal Report, 1973.

9 Barbour AR. Distribution of phosphorus in iron ore deposit of Itabira, Minas Gerais, Brazil, Economic Geology, 1973, p. 11- 13.

10 Peixoto G.m Improvement of the reduction process in $\mathrm{P}$ content and other gangues in iron ore and its agglomerates, International patent, 1991, No 93/10271 Pergamon Press Ltd., $1202 p$

11 Roy R, Agrawal D. Anisothermal Reaction Synthesis of Garnets, Ferrites, and Spinels in Microwave Field". Materials Research Bulletin, 2001

12 Walkiewicz JW, Kazonich G, McGill .L. 1988. Microwave heating characteristics of selected minerals and compounds. Minerals and Metallurgical Processing, 1998; 5 (1), 39-42.

13 Rodrigues MI, Antonio FI, planejamento de experimentos e otimização de processos, casa do pão editora 2005, 618p

14 Haque KE. Microwave energy for mineral treatment processes: um breve resumo, Ottawa, Ontario, Canada, 30p.1998.

15 XIA Wen-tang, REN Zheng-de, GAO Yi-feng Removal of Phosphorus From High Phosphorus Iron Ores by Selective $\mathrm{HCl}$ Leaching Method (School of Metallurgical and Materials Engineering, Chongqing University of Science and Technology, Chongqing 401331 , China 2011.

16 Antonucci V, Correa C. Sulphuric acid leaching of chalcopyrite concentrate assisted by application of microwave energy. Proc. of the Copper 95-Cobre 95, Int. Conf. Vol. 111, Santiago, Chile 1995. 